DOI: $10.1111 /$ jmcb.12690

\author{
MATHIAS KLEIN \\ CHRISTOPHER KRAUSE
}

\title{
Income Redistribution, Consumer Credit, and Keeping Up with the Riches
}

\begin{abstract}
In this study, we set up a dynamic stochastic general equilibrium (DSGE) model with upward looking consumption comparison and show that consumption externalities are an important driver of consumer credit dynamics. Our model economy is populated by two different household types. Investors, who hold the economy's capital stock, own the firms and supply credit, and workers, who supply labor and demand credit to finance consumption. Furthermore, workers condition their consumption choice on the investors' level of consumption. We estimate the model and find a significant keeping up mechanism by matching business cycle statistics. In reproducing credit moments, our proposed model significantly outperforms a model version in which we abstract from consumption externalities.
\end{abstract}

JEL codes: E21, E32, E44

Keywords: income redistribution, consumer credit, relative consumption motive, business cycles

THIS STUDY INVESTIGATES THE RELEVANCE of consumption externalities between different income groups for replicating consumer credit dynamics over the business cycle. For this purpose, we propose a dynamic stochastic general equilibrium (DSGE) model with upward looking consumption comparison that successfully reproduces credit movements during the Great Moderation. We estimate

We thank the editor Sanjay K. Chugh and two anonymous referees for helpful comments and suggestions. This paper has benefited greatly from comments made by participants at many conferences and seminars, in particular from those of Ludger Linnemann, Roland Winkler, Wolfgang Leininger, Wolfram Richter, Philip Jung, Johannes Brumm, Ken Judd, Stefan Wild, Michal Marenčák, Gregor von Schweinitz, Thomas Krause, Geraldine Dany, and Manuel Buchholz. The opinions expressed in this article are the sole responsibility of the authors and should not be interpreted as reflecting the views of Sveriges Riksbank.

MATHIAS KLEIN is a research economist at Sveriges Riksbank (E-mail: Mathias.Klein@ riksbank.se). CHRISTOPHER KRAUSE is a post-doctoral researcher at Karlsruhe Institute of Technology (KIT) (E-mail: christopher.krause@kit.edu).

Received October 1, 2018; and accepted in revised form August 5, 2019.

Journal of Money, Credit and Banking, Vol. 00, No. 0 (xxxx 2020)

(C) 2020 The Authors. Journal of Money, Credit and Banking published by Wiley Periodicals LLC on behalf of Ohio State University

This is an open access article under the terms of the Creative Commons Attribution-NonCommercial-NoDerivs License, which permits use and distribution in any medium, provided the original work is properly cited, the use is non-commercial and no modifications or adaptations are made. 
deep model parameters and thereby contribute to the literature as we show that consumption externalities are a significant determinant of short-run credit fluctuations.

Recent empirical studies show that consumption externalities significantly affect individuals' consumption decisions. Bertrand and Morse (2016) find empirical support for so-called "trickle-down consumption," meaning that rising income and consumption at the top of the income distribution induces households in the lower parts of the distribution to consume a larger share of their income. Focusing on the period between the early 1980s and 2008, the authors present evidence for a negative relationship between income inequality and the savings rate of middle-income households. Carr and Jayadev (2015) show that rising indebtedness of U.S. households is directly related to high levels of income inequality. The authors conclude that relative income concerns explain a significant part of the strong increase in household debt for the period 1999-2009. Using data from the German Socio-Economic Panel, Drechsel-Grau and Schmid (2014) demonstrate that upward looking comparison is a significant determinant of individuals' consumption decisions.

Regarding the interrelation between consumption externalities and private debt dynamics, there is yet no conclusive evidence. Bertrand and Morse (2016) provide indirect evidence that nonrich households rely on easier credit access to finance their desired keeping up with richer coresidents. Moreover, they find a positive relationship between the number of personal bankruptcy filings and top income levels. Georgarakos, Haliassos, and Pasini (2014) show that a higher average income increases the tendency to borrow of households with incomes below average. Contrary, Coibion et al. (2014) find that low-income households in high-inequality regions accumulate less debt than similar households in low-inequality regions. However, their findings are mainly driven by mortgages, whereas for our variable of interest, consumer credit, the authors only find mixed results. Against this background, we investigate this relationship within a structural model and show that relative consumption concerns are an essential driver of aggregate credit dynamics.

Understanding how unsecured consumer credit fluctuates over the business cycle is of central importance because of several reasons. First, consumer credit is an important source of personal finance. For our period of interest, the Great Moderation, ${ }^{1}$ credit averages $23 \%$ of aggregate personal consumption in the United States, indicating that more than one-fifth of households' private expenditures were financed by relying on consumer credit. ${ }^{2}$ Second, short-run credit movements in the United States are characterized by a highly volatile behavior. As Table 1 reports, credit is more than

1. Following Bertrand and Morse (2016) and Iacoviello and Pavan (2013), among others, we date the Great Moderation as the time span between the early 1980s (here 1982 q1) and the outburst of the financial crisis (2008 q2). We choose the Great Moderation as the underlying time span, because this period is characterized by a significant widening of income disparities and several innovations in financial markets, which ultimately made credit access for households easier. Notably, all our qualitative findings are robust when extending the sample by the Great Recession.

2. Our consumer credit measure includes revolving and nonrevolving credit. Revolving credit primarily consists of outstanding credit card balances and accounts for roughly one-third of aggregate consumer credit. Nonrevolving credit includes auto loans as well as consumer installment loans. For a detailed analysis of consumer credit moments across categories and sample periods, we refer the interested reader to Fieldhouse, Livshits, and MacGee (2016). 
TABLE 1

Credit-Related Moments In The U.S. (1982Q1-2008Q2)

\begin{tabular}{lrr}
\hline \hline & $\rho\left(x_{t}, D_{t}\right)$ & $\sigma_{x} / \sigma_{D}$ \\
\hline Output & 0.1523 & 0.4568 \\
Consumption & 0.1658 & 0.2783 \\
Investment & 0.0852 & 1.7524 \\
Hours worked & 0.3603 & 0.5080 \\
Real wage & -0.3207 & 0.3994 \\
\hline
\end{tabular}

Note: $\rho\left(x_{t}, D_{t}\right)$ is the cross-correlation of variable $x$ with credit, $\sigma_{x} / \sigma_{D}$ is the std. deviation of variable $x$ relative to the std. deviation of NoTE: $\rho\left(x_{t}, D_{t}\right)$ is the cross-correlation of variable $x$ with credit, $\sigma_{x} / \sigma_{D}$ is the std. deviation of variable $x$ relative to the std. deviation of
credit. Consumer credit has been deflated using the price index of personal consumption expenditures. All variables are logged and HPfiltered (smoothing parameter of 1600) to obtain cyclical components. For data definitions and sources, see Online Appendix A.

twice (three times) as volatile as output (consumption). Third, and most importantly, business cycle correlations with other main aggregate variables contradict standard theory in which credit represents an instrument to smooth consumption in bad times. Table 1 shows positive comovements between credit and output and consumption, respectively. In contrast to these empirical observations, one would expect countercyclical correlations when credit is primarily used to smooth consumption.

Our proposed model economy is populated by two types of households. Investors, who hold the economy's entire capital stock, own firms, and supply credit, and workers, who supply labor and demand credit to finance their desired level of consumption. Moreover, we include a mechanism through which workers value their own level of consumption relative to the investors' level of consumption. We refer to this mechanism as keeping up with the Riches. ${ }^{3}$ This extension allows us to capture the "trickle-down-consumption" channel of Bertrand and Morse (2016), where the income-poor try to catch up with the income-rich. In the baseline model, fluctuations are driven by four stochastic innovations, namely, a neutral technology, investmentspecific technology, price markup, and wage markup shock. In standard DSGE models, both technology shocks are main drivers of fluctuations in real variables (Smets and Wouters 2003, Justiniano, Primiceri, and Tambalotti 2010). Although in general markup shocks play a minor role in driving output dynamics, we stress their importance in driving credit movements. In particular, in our model setup both innovations shift resources between investors and workers, which in combination with consumption externalities amplifies the credit changes compared to a framework that abstracts from these externalities.

We estimate deep parameters of the four-shock model by a simulated methods of moments (SMM) approach. The parameter measuring the degree of workers' desire to keep up with their richer fellows is estimated to be positive and statistically significant. This leads to the conclusion that keeping up with the Riches is a central driver of credit dynamics over the business cycle. The models' implied credit moments

3. This term is inspired by the literature on keeping up with the Joneses. While studies that incorporate this mechanism model relative consumption concerns in relation to the average consumer (e.g., Galí 1994), in our setup poorer households (workers) aim to keep up with richer ones (investors). 
successfully account for the (targeted) credit statistics as reported in Table 1. Notably, we also find that the estimated model replicates conventional output-related statistics that are not targeted in the estimation. We interpret this result as a further justification of our proposed model.

We perform several robustness checks. First, we show that our model without consumption externalities is not able to generate the observed credit dynamics. A lagged consumption externality, however, which induces a catching up behavior instead of keeping up, matches the targeted moments, but slightly inferior to our baseline specification. Moreover, when accounting for a structural break in the data, we show that (i) our specification successfully accounts for this fact and that (ii) although the strength of the motive has decreased over time, consumption externalities play a crucial role in explaining credit dynamics before and after this break.

When taking a closer look at the dynamics of the estimated model versions, we find that the price markup shock and the investment-specific technology shock produce credit correlations that are qualitatively in line with the empirical ones as reported in Table 1. However, this is only true when we include the consumption externality in the workers' utility function. When we abstract from the relative consumption motive, we find that the model dynamics to both shocks no more correspond to the empirical counterparts. Notably, replicating the positive correlations between credit, output, and consumption does rely on the keeping up mechanism. While recent literature finds that the price markup shock is of minor importance for output dynamics (Justiniano, Primiceri, and Tambalotti 2010), our results indicate that innovations to the price markup, combined with consumption externalities, are essential in replicating short-run credit movements. Concerning the neutral technology shock and the wage markup shock, we find that the model responses do not replicate the empirical credit correlations but the inclusion of these two shocks helps to improve the quantitative performance of the model in terms of credit-related and output-related moments.

Our paper is related to the extensive quantitative literature on consumer credit and bankruptcy, initiated by Chatterjee et al. (2007) and Livshits, MacGee, and Tertilt (2007). ${ }^{4}$ In particular, our study is related to Nakajima and Ríos-Rull (2014) who use a quantitative business cycle model with incomplete markets and the option to default on debt to explain the procyclicality of consumer credit, the countercyclicality of bankruptcy filings, and the high volatility of both. The key ingredient is countercyclical earnings risk, implying that the variance of individual labor productivity is higher during recessions. This countercyclicality leads to higher risk premia on loans during recessions and thus, to a decrease in consumer debt. Fieldhouse, Livshits, and MacGee (2016) use a lifecycle model with incomplete insurance markets and a similar bankruptcy mechanism to explain the business cycle properties of consumer credit and bankruptcies. The authors find that only the addition of so-called intermediation shocks, that is, exogenous countercyclical shocks to the cost of funds for lenders, can generate procyclical borrowing and countercyclical bankruptcy filings. The mechanism behind this finding is that the intermediation shock increases the risk-free

4. See Livshits (2015) for an excellent overview. 
interest rate during recessions, simultaneously the cost of a loan, and thus, leads to a decrease in borrowing.

We propose a different mechanism, which is based on recent microeconometric evidence (Bertrand and Morse 2016), to account for consumer credit dynamics. However, we regard these different mechanisms as complementary, rather than competing or mutually exclusive explanations for consumer credit fluctuations.

The rest of the paper is organized as follows. Section 1 presents the baseline model. In Section 2, we introduce functional forms and show a set of theoretical results that connect the strength of the keeping up mechanism to a set of deep model parameters. Section 3 describes the calibration and estimation strategy as well as our numerical results. In Section 4, we provide a detailed analysis of the implied model dynamics. In Section 5, we conduct two important robustness tests. First, we show that our baseline results are not affected by introducing a lagged consumption externality. Second, we split the sample and show that, although the degree of upward looking comparisons has decreased over time, it is still a significant factor of credit dynamics. Finally, Section 6 concludes.

\section{THE MODEL ECONOMY}

In this section, we construct our baseline model that allows consumption externalities to influence the choices of households and that assesses its role within the business cycle. The economy is populated by a continuum of firms producing differentiated intermediate goods, a representative final good firm, and a representative labor bundler. There are two types of households, investors and workers, who are distinguished by their source of income as well as their access to capital and asset markets. Finally, a financial intermediary issues deposits to investors and loans to workers.

\subsection{Final Good Firms}

In this perfectly competitive sector, a representative firm produces final consumption good $Y_{t}$, combining a continuum of intermediate goods $Y_{t}(l), l \in[0,1]$, using the constant returns to scale technology

$$
Y_{t}=\left[\int_{0}^{1} Y_{t}(l)^{\frac{1}{\mu_{t}}} d l\right]^{\mu_{t}},
$$

with $\mu_{t}>1$. The time-varying price markup $\mu_{t}$ is a function of the elasticity of substitution between intermediate goods and follows an exogenous stochastic process around its steady-state value $\bar{\mu}$ given by

$$
\log \mu_{t}=\left(1-\rho_{\mu}\right) \log \bar{\mu}+\rho_{\mu} \log \mu_{t-1}+\varepsilon_{\mu, t},
$$


where $\varepsilon_{\mu, t} \stackrel{\text { i.i.d. }}{\sim} \mathcal{N}\left(0, \sigma_{\mu}^{2}\right)$, and $\left|\rho_{\mu}\right|<1$. The firm chooses intermediate inputs to maximize profits subject to (1), which yields the demand function for intermediate $\operatorname{good} Y_{t}(l)$,

$$
Y_{t}(l)=Y_{t}\left(\frac{P_{t}(l)}{P_{t}}\right)^{\frac{\mu_{t}}{1-\mu_{t}}},
$$

and subsequently the price index of the final good,

$$
P_{t}=\left[\int_{0}^{1} P_{t}(l)^{\frac{1}{1-\mu_{t}}} d l\right]^{1-\mu_{t}} .
$$

\subsection{Intermediate Goods Firms}

Each intermediate good is produced by a monopolistically competitive firm according to a production function given by

$$
Y_{t}(l)=z_{t} F\left(K_{t-1}(l), N_{t}(l)\right),
$$

where we assume that $F$ is strictly increasing, twice differentiable in both arguments, exhibits constant returns to scale, and satisfies the Inada conditions. $K_{t-1}(l)$ and $N_{t}(l)$ denote the quantities of capital and labor services utilized to produce intermediate good $Y_{t}(l) . z_{t}$ is the technology level common across all firms. We assume that $z_{t}$ follows an exogenous stochastic process around its steady-state value $\bar{z}$,

$$
\log z_{t}=\left(1-\rho_{z}\right) \log \bar{z}+\rho_{z} \log z_{t-1}+\varepsilon_{z, t},
$$

where $\varepsilon_{z, t} \stackrel{i . i . d .}{\sim} \mathcal{N}\left(0, \sigma_{z}^{2}\right)$, and $\left|\rho_{z}\right|<1$. Intermediate goods firms maximize profits, defined by

$$
\Pi_{t}(l)=Y_{t}(l)-R_{t} K_{t-1}(l)-W_{t} N_{t}(l)
$$

subject to the demand function (3) and to cost minimization, where $R_{t}$ is the rental rate of physical capital and $W_{t}$ is the aggregate wage rate. We assume symmetry such that firms charge the same prices and choose the same production inputs. Prices are perfectly flexible, which yields marginal costs that are equal to $1 / \mu_{t}$. Thus, the aggregate wage rate can be expressed as a function of the marginal product of labor $M P L_{t}$ and $\mu_{t}$,

$$
W_{t}=\frac{M P L_{t}}{\mu_{t}}
$$


The aggregate rental rate of physical capital equals

$$
R_{t}=\frac{M P K_{t}}{\mu_{t}},
$$

where $M P K_{t}$ is the marginal product of capital.

Following Chari, Kehoe, and McGrattan (2007), among others, $\mu_{t}$ can also be interpreted as the labor wedge on the firm side, as it drives a wedge between the wage rate and the marginal product of labor.

In the following sections, it will become apparent that the price markup shock shifts income from the poor to the rich households. Thus, we refer to (2) as a redistribution shock..$^{5}$

\subsection{Employment Agency}

As in Erceg, Henderson, and Levin (2000), we assume that each working household $j$ is a monopolistic supplier of a differentiated labor service $N_{w, t}(j)$. A representative labor bundler, termed as employment agency, combines the intermediate labor services into a homogeneous labor input $N_{w, t}$ using the constant returns to scale technology

$$
N_{w, t}=\left[\int_{0}^{1} N_{w, t}(j)^{\frac{1}{v_{t}}} d j\right]^{v_{t}}
$$

with $v_{t}>1$. The time-varying wage markup $v_{t}$ is a function of the elasticity of substitution between labor types and follows an exogenous stochastic process around its steady-state value $\bar{v}$,

$$
\log v_{t}=\left(1-\rho_{\nu}\right) \log \bar{v}+\rho_{\nu} \log v_{t-1}+\varepsilon_{v, t},
$$

where $\varepsilon_{v, t} \stackrel{i . i . d .}{\sim} \mathcal{N}\left(0, \sigma_{v}^{2}\right)$, and $\left|\rho_{\nu}\right|<1$. The labor bundler operates in a perfectly competitive market and minimizes the cost of a given amount of aggregate labor $N_{w, t}$, taking each household's wage rate $W_{t}(j)$ as given, leading to the labor demand function

$$
N_{w, t}(j)=N_{w, t}\left(\frac{W_{t}(j)}{W_{t}}\right)^{\frac{v_{t}}{1-v_{t}}},
$$

where $W_{t}$ is the aggregate wage index. By substituting (12) into (10), we obtain the following expression for the latter,

$$
W_{t}=\left[\int_{0}^{1} W_{t}(j)^{\frac{1}{1-v_{t}}} d j\right]^{1-v_{t}} .
$$

5. Throughout the paper, we use the two terms redistribution shock and price markup shock interchangeably. 


\subsection{Households}

Our model economy is populated by a continuum of infinitely lived households, indexed on the unit interval. A fraction $\chi$ of households is born as investors (subscript $i$ ), holds the entire stock of physical capital, and owns firms. The remaining fraction $1-\chi$ is born as workers (subscript $w$ ), makes up the entire labor force, and does not have access to capital or stock markets. However, workers can get a credit from financial intermediaries, which helps them to finance their desired level of consumption.

Investors. The preferences of investors are given by their expected lifetime utility

$$
E_{0} \sum_{t=0}^{\infty} \beta_{i}^{t} U_{i}\left(C_{i, t}\right)
$$

where $\beta_{i} \in(0,1)$ is the specific discount factor of investors, $U_{i}(\cdot)$ is the period utility function, and $E_{0}$ is the expectations operator with respect to information in period 0 . Since investors do not supply labor, we assume that the level of consumption is the only argument of the investors' utility function.

DEFINITION 1 (Investors' utility function). We impose the following assumptions on the investors' utility function $U_{i}$.

(i) $\frac{\partial U_{i}}{\partial C_{i}}>0, \frac{\partial^{2} U_{i}}{\left(\partial C_{i}\right)^{2}}<0$,

(ii) $\lim _{C_{i} \rightarrow \infty} \frac{\partial U_{i}}{\partial C_{i}}=0, \lim _{C_{i} \searrow 0} \frac{\partial U_{i}}{\partial C_{i}}=\infty$.

Assumption (i) states that the utility function is strictly increasing, twice differentiable, and strictly concave in the investors' level of consumption. Assumption (ii) ensures that the Inada conditions hold.

Investors can hold two different assets. They are the sole owner of the capital stock, which is rented to intermediate goods firms at rate $R_{t}$, and they have a riskless savings account at the financial intermediary. For each unit of savings, the investor gets an interest of $i^{d}$. The investors' budget constraint is then given by

$$
C_{i, t}+I_{i, t}+Q_{t}^{d} D_{i, t} \leq D_{i, t-1}+R_{t} K_{i, t-1}+\frac{\Pi_{t}}{\chi}
$$

where $I_{i, t}$ denotes investment, $D_{i, t} \in \mathbb{R}_{+}$are deposits, $Q_{t}^{d}:=1 /\left(1+i_{t-1}^{d}\right) \in(0,1)$, with $i_{t}^{d}$ being the interest received, and $\Pi_{t} / \chi$ is the individual share of profits from ownership of firms. The law of motion for physical capital is

$$
K_{i, t}=(1-\delta) K_{i, t-1}+\zeta_{t} I_{i, t},
$$

where $\delta$ is the depreciation rate. $\zeta_{t}$ denotes a shock to the relative price of investment in terms of the consumption good. We assume that the shock follows an AR 
(1)-process around its steady-state value $\bar{\zeta}$,

$$
\log \zeta_{t}=\left(1-\rho_{\zeta}\right) \log \bar{\zeta}+\rho_{\zeta} \log \zeta_{t-1}+\varepsilon_{\zeta, t},
$$

where $\varepsilon_{\zeta, t} \stackrel{i . i . d .}{\sim} \mathcal{N}\left(0, \sigma_{\zeta}^{2}\right)$, and $\left|\rho_{\zeta}\right|<1$. The investors' optimization problem is then given by the objective function (14), which is maximized subject to (15) and (16) so that the first-order conditions are given by

$$
\Lambda_{i, t}=U_{i}^{\prime}\left(C_{i, t}\right),
$$

$$
\Lambda_{i, t}=\beta_{i} E_{t} \zeta_{t} \Lambda_{i, t+1}\left(R_{t+1}+\frac{1-\delta}{\zeta_{t+1}}\right)
$$

$$
\Lambda_{i, t} Q_{t}^{d}=\beta_{i} E_{t} \Lambda_{i, t+1},
$$

where $U_{i}^{\prime}(\cdot)$ denotes the first derivative of the utility function with respect to the argument in brackets, and $\Lambda_{i, t}$ denotes the Lagrange multiplier associated with (15). Finally, the transversality conditions that rule out infinite wealth accumulation, given by

$$
\begin{aligned}
& \lim _{j \rightarrow \infty} E_{t} \beta^{j} \Lambda_{i, t+j} K_{i, t+j}=0, \\
& \lim _{j \rightarrow \infty} E_{t} \beta^{j} \Lambda_{i, t+j} Q_{t+j}^{d} D_{i, t+j}=0,
\end{aligned}
$$

are required to hold.

Workers. The preferences of worker $j$ are given by his expected lifetime utility

$$
E_{0} \sum_{t=0}^{\infty} \beta_{w}^{t} U_{w}\left(C_{w, t}(j), X_{t}(j), N_{w, t}(j)\right),
$$

where $\beta_{w} \in(0,1)$ is the specific discount factor of workers, $U_{w}(\cdot)$ is the period utility function, $C_{w, t}(j)$ is the workers' consumption level, and $X_{t}(j)$ is a consumption externality that is strictly positive and that workers take as given. In each period, workers are endowed with one unit of time that is allocated between leisure $L_{w, t}(j)$ and individual labor services $N_{w, t}(j)$.

DEFINITION 2 (Worker's utility function). We impose the following assumptions on the workers' utility function $U_{w}$.

(i) $\frac{\partial U_{w}}{\partial C_{w}}>0, \frac{\partial^{2} U_{w}}{\left(\partial C_{w}\right)^{2}}<0, \frac{\partial U_{w}}{\partial N_{w}}<0, \frac{\partial^{2} U_{w}}{\left(\partial N_{w}\right)^{2}}<0$,

(ii) $\frac{\partial^{2} U_{w}}{\left(\partial C_{w}\right)^{2}} \frac{\partial^{2} U_{w}}{\left.\partial N_{w}\right)^{2}}-\left(\frac{\partial^{2} U_{w}}{\partial C_{w} \partial N_{w}}\right)^{2}>0$, 
(iii) $\lim _{C_{w} \rightarrow \infty} \frac{\partial U_{w}}{\partial C_{w}}=0, \lim _{C_{w} \searrow 0} \frac{\partial U_{w}}{\partial C_{w}}=\infty$,

(iv) $\frac{\partial U_{w}}{\partial X}<0 \vee \frac{\partial U_{w}}{\partial X}>0$,

(v) $\frac{\partial M R S_{w}}{\partial X}>0 \vee \frac{\partial M R S_{w}}{\partial X}<0$, where $M R S_{w}:=-\frac{\partial U_{w} / \partial L_{w}}{\partial U_{w} / \partial C_{w}}$.

Assumptions (i), (ii), and (iii) refer to the standard properties of utility functions, namely, that they are twice differentiable, strictly increasing in consumption, strictly decreasing in labor, strictly concave in these two variables, and that Inada conditions are satisfied. The key issue here is the role of the consumption externality in (iv) and (v) ${ }^{6}$ Assumption (v) specifies the effect of $X$ in terms of the marginal rate of substitution $(M R S)$ between leisure and consumption. We say that preferences exhibit keeping up with the Riches, if the MRS is increasing in $X$ (first argument of (v)). This implies that a rise in the consumption externality may raise the worker's marginal utility of consumption relative to leisure, leading the worker to work more hours if prices are fixed. Preferences that feature the opposite effect are termed running away from the Riches (second argument of (v)). ${ }^{7}$ Note that assumption (iv) is necessary for (v) but not vice versa.

Including this consumption externality mechanism is motivated by recent microeconometric studies, which find that upward looking comparison significantly affects individuals' consumption decisions (Drechsel-Grau and Schmid 2014, Bertrand and Morse 2016, Carr and Jayadev 2015).

Workers face the following budget constraint,

$$
C_{w, t}(j)+D_{w, t-1}(j) \leq W_{t}(j) N_{w, t}(j)+Q_{t}^{b} D_{w, t}(j)-\frac{\phi}{2}\left(D_{w, t}(j)-\bar{D}_{w}\right)^{2},
$$

where $D_{w, t}(j) \in \mathbb{R}_{+}$denotes received credit at price $Q_{t}^{b}:=1 /\left(1+i_{t-1}^{b}\right) \in(0,1)$, with $i_{t}^{b}$ being the interest paid, and $W_{t}(j)$ is the individual wage rate of household $j$. The last term of (24) represents a quadratic cost of choosing a quantity of credit different from the steady-state value $\bar{D}_{w}$. This assumption can be thought of as a kind of transaction cost and is needed to rule out random walk components in the equilibrium dynamics of credit. ${ }^{8}$ To rule out Ponzi schemes, we impose

$$
\lim _{j \rightarrow \infty} E_{t} \prod_{s=0}^{j} Q_{t+s}^{b} D_{w, t+j} \leq 0 .
$$

The optimization problem of working household $j$ is then given by the objective function (23) subject to (24), (25), and the demand for the household's differentiated

6. Following Dupor and Liu (2003), preferences exhibit jealousy if the worker derives disutility from an increase in the externality (first argument of (iv)), and admiration if the opposite is true (second argument of (iv)).

7. For specific preferences that are additively separable in $\left(C_{w}, X\right)$ and $L_{w}$, assumption (v) is equivalent to $\left[\partial^{2} U_{w} /\left(\partial C_{w} \partial X\right)\right] /\left[\partial U_{w} / \partial C_{w}\right] \gtrless 0$, as used by Galí (1994), but in general this is not the case.

8. Similar to our problem, Schmitt-Grohé and Uribe (2003) compare different modeling strategies that induce stationarity within small open economy models. 
labor input (12). We assume symmetric working households such that all workers set the same wage, supply the same amount of labor, and choose the same amount of consumption and credit. As for the final good price, we assume that wages are perfectly flexible.

Letting $\Lambda_{w, t}$ be the workers' Lagrange multiplier on their budget constraint, the symmetric optimal choices for consumption, labor supply, and credit demand are then ultimately determined by

$$
\begin{aligned}
& \Lambda_{w, t}=U_{w}^{\prime}\left(C_{w, t}\right), \\
& \Lambda_{w, t} W_{t}=-U_{w}^{\prime}\left(N_{w, t}\right) v_{t}, \\
& \Lambda_{w, t}\left[Q_{t}^{b}-\phi\left(D_{w, t}-\bar{D}_{w}\right)\right]=\beta_{w} E_{t} \Lambda_{w, t+1},
\end{aligned}
$$

where $U_{w}^{\prime}(\cdot)$ denotes the first derivative of the utility function with respect to the argument in brackets.

From (27), it is apparent that the wage rate is a function of the marginal rate of substitution between leisure and consumption, $M R S_{t}$, and the wage markup $v_{t}$,

$$
W_{t}=v_{t} M R S_{t} .
$$

In close analogy to the price markup, $v_{t}$ can be interpreted as the labor wedge on the household side. In a perfectly competitive economy, $\mu_{t}$ and $v_{t}$ would be one such that wages equal the marginal product of labor on the one hand, and the marginal rate of substitution on the other.

\subsection{Financial Intermediaries}

There is a representative financial intermediary that issues one-period deposits to investors and one-period loans to workers. We follow Cúrdia and Woodford (2010) by assuming that this type of intermediation is costly. ${ }^{9}$ In particular, we assume that the following condition describes the financing of the intermediary,

$$
D_{t}=B_{t}+\Psi\left(B_{t}\right),
$$

where $D_{t}$ are aggregate deposits, $B_{t}$ are aggregate loans, and $\Psi(\cdot)$ are intermediation costs. ${ }^{10}$ Equation (30) states that deposits at period $t$ have to cover loans at period $t$, including the costs of intermediation. The intermediary then maximizes profits, given by

$$
\max _{D_{t}, B_{t}}\left\{\left(1-Q_{t}^{b}\right) B_{t}-\left(1-Q_{t}^{d}\right) D_{t}\right\}
$$

9. These costs include, for example, operating costs, but are also supposed to capture default risk.

10. Following Cúrdia and Woodford (2010), we assume that $\Psi(\cdot)$ is positive and twice differentiable for $B>0$, with $\Psi(0)=0, \partial \Psi / \partial B>0$, and $\partial^{2} \Psi /(\partial B)^{2}>0$. 
subject to (30). Perfect competition then yields the following first-order condition

$$
\left(1-Q_{t}^{b}\right)-\left(1-Q_{t}^{d}\right) \frac{\partial \Psi\left(B_{t}\right)}{\partial B_{t}}=1-Q_{t}^{d},
$$

implying that the gains from one additional unit of loans are equal to the cost of one additional unit of deposits. We use this optimality condition to define a spread $\varpi$ between the interest rates in the following way,

$$
1-Q_{t}^{b}=\left(1-Q_{t}^{d}\right)\left(1+\varpi_{t}\right)
$$

where $\varpi_{t}:=\partial \Psi\left(B_{t}\right) / \partial B_{t}$. It follows from the properties of $\Psi$ that $\varpi_{t}$ is strictly larger than zero and increasing in the amount of aggregate loans for $B_{t}>0$, and subsequently, that the borrowing interest rate has to be strictly larger than the interest rate on deposits.

\subsection{Aggregation and Market Clearing}

Aggregates are defined as the weighted average of the respective variables for each household type. Hence, we get

$$
\begin{aligned}
& C_{t}=\chi C_{i, t}+(1-\chi) C_{w, t}, \\
& I_{t}=\chi I_{i, t} .
\end{aligned}
$$

The markets for capital and labor clear when

$$
\begin{aligned}
& K_{t}=\chi K_{i, t}, \\
& N_{t}=(1-\chi) N_{w, t},
\end{aligned}
$$

at their respective prices $R_{t}$ and $W_{t}$, deposit and credit market clearing require that

$$
D_{t}=\chi D_{i, t}
$$

$$
B_{t}=(1-\chi) D_{w, t},
$$

at prices $Q_{t}^{d}$ and $Q_{t}^{b}$, while the aggregate resource constraint is given by

$$
Y_{t}=C_{t}+I_{t}+(1-\chi) \frac{\phi}{2}\left(D_{w, t}-\bar{D}_{w}\right)^{2}+\Psi\left(B_{t}\right) .
$$




\subsection{Equilibrium}

In this section, we define the equilibrium for the economy described above.

DEFINITION 3 (Competitive equilibrium). Given the exogenous realizations of $\left\{\zeta_{t}\right.$, $\left.\mu_{t}, z_{t}, v_{t}\right\}_{t=0}^{\infty}$, a competitive rational expectations equilibrium is a stochastic set of sequences

$\left\{C_{t}, C_{i, t}, C_{w, t}, D_{i, t}, D_{w, t}, I_{t}, I_{i, t}, K_{t}, K_{i, t}, \Lambda_{i, t}, \Lambda_{w, t}, N_{t}, N_{w, t}, \Pi_{t}, Q_{t}^{b}, Q_{t}^{d}, R_{t}, W_{t}, Y_{t}, D_{t}, B_{t}\right\}_{t=0}^{\infty}$

satisfying

(i) the investors' first-order conditions (18)-(20), with binding budget constraint (15) and transversality conditions (21) and (22),

(ii) the workers' first-order conditions (26)-(28), with binding budget constraint (24) and binding no-Ponzi condition (25),

(iii) factor prices (8) and (9), capital accumulation (16), profits definition (7), and production technology (5),

(iv) the financial intermediaries' first-order condition (32) as well as condition (30),

(v) the aggregation identities (34) and (35), and

(vi) the market clearing condition for capital (36), labor (37), deposits (38), and loans (39).

The model is solved by a log-linear approximation around its deterministic steady state.

\section{THEORETICAL RESULTS}

The next subsection presents our choice of functional forms for the production technology and the utility functions, as well as some qualitative results that connect the strength of the keeping up mechanism with two model parameters.

\subsection{Functional Forms}

The investors' period utility function is given by

$$
U_{i}\left(C_{i}\right)=\log C_{i},
$$

while the workers' period utility function is assumed to be

$$
U_{w}\left(C_{w}, X, N_{w}\right)=\frac{\left(C_{w} X^{-b}\right)^{1-\sigma}-1}{1-\sigma}-\frac{\gamma N_{w}^{1+\eta}}{1+\eta}
$$

where $b$ indicates the strength of the consumption externality, $\sigma$ is a risk aversion parameter, $\gamma$ is a scaling parameter, and $\eta$ denotes the inverse Frisch elasticity of 
labor supply. This specification implies that $M R S_{t}=\gamma N_{w, t}^{\eta} / \Lambda_{w, t}$. We assume that $X$ is defined as

$$
X_{t}:=\frac{C_{i, t}}{C_{w, t}}
$$

such that workers value the contemporaneous consumption level of investors relative to their own. ${ }^{11}$ The sign of $b$ then ultimately determines if preferences exhibit jealousy or admiration. If $b$ is positive, $U_{w}$ implies jealousy, while for negative values, the conditions for admiration are met.

In the following, we exclude the case of $\sigma=1$. Assuming a logarithmic form for the first part of the workers' utility function would imply that the marginal rate of substitution between consumption and leisure is independent of the consumption externality. This is a violation of condition (v) in Definition 2 and therefore, we assume that $\sigma>0$ and $\sigma \neq 1$.

The magnitude of $\sigma$ and the sign of $b$ are of crucial importance whether working households aim to keep up with the investors or if they are running away. This relationship can be expressed by $\operatorname{sgn}\left(\partial U_{w} / \partial X\right)=\operatorname{sgn}(b(1-\sigma))$. In particular, there are the four different cases $\{b>0, \sigma>1\},\{b<0, \sigma \in(0,1)\},\{b>0, \sigma \in(0,1)\}$, and $\{b<0, \sigma>1\}$. While the first two cases imply that workers wish to keep up, the latter imply running away. As our estimations below indicate, only the first case is relevant.

Intermediate good firms produce according to the Cobb-Douglas production function

$$
Y_{t}=z_{t} K_{t-1}^{\alpha} N_{t}^{1-\alpha}
$$

where $\alpha \in[0,1]$ measures the output elasticity of capital. This specification implies that $M P L_{t}=(1-\alpha) Y_{t} / N_{t}$ and $M P K_{t}=\alpha Y_{t} / K_{t-1}$.

We follow Cúrdia and Woodford (2010) and set the functional form for intermediation costs as

$$
\Psi\left(B_{t}\right)=\psi B_{t}^{\kappa},
$$

where $\psi$ is a positive constant and $\kappa$ can be interpreted as the elasticity of loans.

\subsection{A First Set of Results}

The following two results clarify the role of $b$ and $\sigma$ on shaping the behavior of working households and consequently, their role for the cyclical properties of our economy. We first present the workers' specific consumption Euler equation, which

11. Similar specifications of relative consumption motives are used by Airaudo and Bossi (2017) and Alvarez-Cuadrado and Japaridze (2017). They study how consumption externalities affect the impact of monetary policy and financial deregulation, respectively. In a later section, we show that our results are robust when modeling the externality based on lagged consumption levels. 
relates the consumption growth of investors and changes in the credit price to their own consumption growth. Afterward, we analytically derive the response of the workers' consumption to a marginal increase in the investors' consumption level. The result is of particular importance to our quantitative analysis in the following, as we are then be able to compare our result to related empirical findings of Bertrand and Morse (2016).

Proposition 1. Suppose that the consumption externality is given by (43) and abstracting from debt adjustment costs, the workers' log-linearized Euler equation is given by

$$
\widehat{C}_{w, t+1}-\widehat{C}_{w, t}=-\frac{1}{\sigma+b(\sigma-1)} \widehat{Q}_{t}^{b}+\frac{b(\sigma-1)}{\sigma+b(\sigma-1)}\left(\widehat{C}_{i, t+1}-\widehat{C}_{i, t}\right),
$$

where a circumflex indicates log-deviations from the respective steady-state value.

This proposition shows that the workers' intertemporal consumption choice is determined by two channels, consumption smoothing and the keeping up motive. Since workers do not have access to capital markets, they are not able to transfer their income between periods so that the only option to smooth consumption is via credit. A high $\sigma$ therefore implies that fluctuations in the price of credit have less influence on the consumption decision and the respective household prefers a smooth consumption profile. The strength of consumption smoothing in our setting is jointly determined by $\sigma$ and $b$. In this sense, a positive $b$ amplifies the consumption smoothing motive of workers, as long as $\sigma>1$.

On the other hand, $\sigma$ also affects the strength of the keeping up motive, as can be seen in the second term on the right-hand side of (46). A positive $b$ then implies that the keeping up motive is increasing in $\sigma$. If $b$ is equal to zero, the keeping up channel is shut down and consumption smoothing is only determined by $\sigma$.

The following proposition characterizes the influence of $b$ on the worker's consumption decision when there is an increase in the investor's consumption level.

Proposition 2. Suppose that $\sigma>1$. Given an exogenous one-time change in investor's consumption $d \widehat{C}_{i, t}$, the worker's consumption response is given by

$$
d \widehat{C}_{w, t}=\xi_{0} d \widehat{C}_{i, t}
$$

where $\xi_{0}:=\frac{\frac{b(\sigma-1)}{\eta}\left(\bar{W} \bar{N}_{w}+\frac{\left(\bar{Q}^{b}\right)^{2}}{\phi}\right)}{\frac{(\sigma+b(\sigma-1))}{\eta}\left(\bar{W} \bar{N}_{w}+\frac{\left(\bar{Q}^{b}\right)^{2}}{\phi}\right)+\bar{C}_{w}}, \quad$ and $\quad\left|\xi_{0}\right| \in(0,1)$.

Proof. See Online Appendix B.

This proposition states that the (partial equilibrium) response of workers is determined by $b$ and $\sigma$, besides a few positive steady-state values and the labor supply elasticity. Unsurprisingly, the response is zero if $b$ is equal to zero. This expression is of particular importance in our numerical analysis below, as we use it to compare this value to the values found in Bertrand and Morse (2016). 
TABLE 2

Model Calibration

\begin{tabular}{lccl}
\hline \hline & Parameter & Value & \multicolumn{1}{c}{ Target } \\
\hline $\begin{array}{l}\text { Preferences } \\
\text { Investors' discount factor }\end{array}$ & $\beta_{i}$ & 0.995 & $\begin{array}{l}\text { Annual real interest rate of 2\% } \\
\text { Credit-to-labor income of 27\% }\end{array}$ \\
$\begin{array}{l}\text { Workers' discount factor } \\
\text { Inverse Frisch elasticity }\end{array}$ & $\beta_{w}$ & 0.994 & $\begin{array}{l}\text { Hall (2009) } \\
\text { Disutility of labor }\end{array}$ \\
$\begin{array}{l}\text { SS labor supply of 0.33 } \\
\text { Traction of investors }\end{array}$ & $\gamma$ & 1.000 & Bertrand and Morse (2016) \\
Technology & $\chi$ & 5817.827 & Capital share of income of 26\% \\
Capital share & $\alpha$ & 0.200 & Annual depreciation of 10\% \\
$\begin{array}{l}\text { Depreciation rate } \\
\text { Credit friction }\end{array}$ & $\delta$ & 0.330 & SS credit spread of 2\% \\
Intermed. cost constant & $\psi$ & 0.025 & Cúrdia and Woodford (2010) \\
Loan elasticity & $\kappa$ & 2.629 & 48\% income share of investors \\
Steady-state & & 5.000 & Schmitt-Grohé and Uribe (2011) \\
Price markup & $\bar{v}$ & 1.250 & Normalization \\
Wage markup & $\bar{\mu}$ & 1.100 & Normalization \\
Labor & $\bar{N}$ & 0.330 & Normalization \\
Neutral technology & $\bar{z}$ & 1.000 & \\
Inv.-spec. technology & $\bar{\zeta}$ & 1.000 & \\
\hline & & &
\end{tabular}

\section{PARAMETERIZATION}

We use an SMM approach to estimate a subset of the structural parameters of the model. Of particular importance are the parameters that determine the impact of the relative consumption motive, namely, $b$ and $\sigma$. The characteristics of the neutral technology shock and the redistribution shock are estimated by ordinary least squares. The parameters that are not estimated are calibrated in a standard fashion.

\subsection{Calibrated Parameters}

Table 2 reports the calibrated parameter values, where an upper bar denotes the steady-state value of the respective variable. One model period corresponds to one quarter.

The discount factor of investors is set to 0.995 to match an annual steady-state real interest rate of $2 \%$. Workers have a discount factor of 0.994 to match a steady-state credit-to-labor income ratio of $27 \%$, which is the average for the Great Moderation. We choose an inverse Frisch elasticity $\eta$ of 1 , which is in the range of values suggested by Hall (2009). We normalize the steady-state level of labor supply to 0.33 and set $\gamma$ accordingly.

To ensure comparability to the empirical study of Bertrand and Morse (2016), the share of investors (rich households) in the overall population $\chi$ is set to $20 \%{ }^{12}$; $\alpha$ equals 0.33 , implying a steady-state capital share of income of about $26 \%$. The

12. The same ratio of workers-to-capital owners is chosen by Lansing and Markiewicz (2018). 
depreciation rate of capital $\delta$ equals 0.025 , which corresponds to an annual depreciation rate on capital equal to $10 \%$.

The intermediation cost function includes two parameters. For $\phi$, we choose a value of 2.629 to generate a steady-state credit spread of $2 \%$ (annualized). The loan elasticity $\kappa$ is set to 5 as in Cúrdia and Woodford (2010).

We assign a value of 1.25 to the steady-state price markup to match an investors' income share of $48 \% .{ }^{13}$ For the steady-state wage markup, we follow Schmitt-Grohé and Uribe (2011) and choose 1.1, which is in the interval of typically used values in the literature. The steady-state levels $\bar{z}$ and $\bar{\zeta}$ are normalized to 1 .

\subsection{OLS Estimation}

In line with the construction of the empirical moments reported in Table 1, the sample for the OLS estimation covers the period 1982q1 to 2008q2. With the exception of the TFP series, all data series mentioned in the following are obtained from the FRED database. ${ }^{14}$

TFP data are taken from Fernald (2014). This quarterly series on aggregate technology controls for aggregation effects, varying utilization of capital and labor, nonconstant returns, and imperfect competition. The variable is detrended before estimation by a one-sided HP-filter, as suggested by Stock and Watson (1999), with a smoothing value of 1,600. The estimated AR-coefficient and standard deviation are 0.837 and 0.008 , respectively. These estimates are similar to the findings of Bullard and Singh (2012) who use the standard (unadjusted) Solow residual to calculate the shock characteristics.

For constructing a time series of the price markup, we follow Galí, Gertler, and López-Salido (2007) and use the following equation,

$$
\mu_{t}=M P L_{t}-w_{t},
$$

where the marginal product of labor $M P L_{t}$ equals $\log \left[(1-\alpha) y_{t} / n_{t}\right] . y_{t} / n_{t}$ is measured as the real output per hour worked of all persons in the nonfarm business sector, and $w_{t}$ is the log of real compensation per hour in this sector. Again, all series are detrended by the one-sided HP-filter. The estimates of the AR-coefficient and the standard deviation are 0.777 and 0.006 , respectively, and thus, similar to those of Galí, Gertler, and López-Salido (2007) and Karabarbounis (2014). The upper part of Table 3 summarizes the parameter values estimated by OLS.

\subsection{SMM Estimation}

According to equation (29), the wage markup $v_{t}$ is defined as the product of the real wage rate $W_{t}$ and the marginal rate of substitution $M R S_{t}$. Given the specific utility

13. This value is taken from the Current Population Survey (CPS) for the years from 1982 to 2007.

14. See Online Appendix A for a detailed description of the data. 
TABLE 3

Estimated Parameter Values

\begin{tabular}{|c|c|c|c|c|}
\hline & Parameter & \multicolumn{2}{|c|}{ Value } & $S D$ \\
\hline \multicolumn{5}{|l|}{ OLS estimation } \\
\hline AR(1)-coefficient technology shock & $\rho_{z}$ & \multicolumn{2}{|c|}{0.8368} & $(0.0554)$ \\
\hline Standard deviation technology shock & $\sigma_{z}$ & \multicolumn{2}{|c|}{0.0084} & $(0.0031)$ \\
\hline AR(1)-coefficient redistribution shock & $\rho_{\mu}$ & \multicolumn{2}{|c|}{0.7769} & $(0.0629)$ \\
\hline \multirow[t]{2}{*}{ Standard deviation redistribution shock } & $\sigma_{\mu}$ & \multicolumn{2}{|c|}{0.0063} & $(0.0024)$ \\
\hline & Parameter & Prior & Value & $S D$ \\
\hline Relative consumption motive & $b$ & 0.0000 & 2.9198 & $(0.1708)$ \\
\hline Risk aversion parameter & $\sigma$ & 2.0000 & 4.1754 & $(0.1658)$ \\
\hline Debt adjustment cost parameter & $\phi$ & 0.0000 & 0.9961 & $(0.0072)$ \\
\hline AR-coefficient inv.-spec. technology shock & $\rho_{\zeta}$ & 0.5000 & 0.9181 & $(0.0029)$ \\
\hline Standard deviation investment shock & $\sigma_{\zeta}$ & 0.0050 & 0.0102 & $(0.0001)$ \\
\hline AR-coefficient wage markup shock & $\rho_{v}^{3}$ & 0.5000 & 0.6080 & $(0.0378)$ \\
\hline Standard deviation wage markup shock & $\sigma_{v}$ & 0.0050 & 0.0281 & $(0.0009)$ \\
\hline
\end{tabular}

function of working households,

$$
M R S_{t}=\frac{\gamma N_{w, t}^{\eta}}{\Lambda_{w, t}}, \quad \text { where } \Lambda_{w, t}=C_{w, t}^{-\sigma} X_{t}^{b(\sigma-1)} .
$$

Calculating a wage markup series would require data on $C_{i}$ and $C_{w}$, and an appropriate value for $b$, the parameter measuring the strength of the relative consumption motive. However, since there is no such data available, to the best of our knowledge, and there is little guidance in the literature about values for $b$, we use the SMM estimator to overcome this data problem. ${ }^{15}$ The objective of SMM is to find a parameter vector that minimizes the weighted distance between simulated model moments and their empirical counterparts.

Let $\widehat{\Omega}$ be a $k \times 1$ vector of empirical moments computed from the data and let $\Omega(\theta)$ be the $k \times 1$ vector of simulated moments computed from artificial data. The corresponding time series are generated from simulating the model given a draw of random shocks and the $p \times 1$ vector $\theta \in \Theta$, with $\Theta \subseteq \mathbb{R}^{p}$. The length of the simulated series is $\tau T$, where $T$ is the number of observations in the real data set and $\tau \geq 1$ is an integer. Then, the SMM estimator is given by

$$
\tilde{\theta}_{S M M}=\underset{\theta \in \Theta}{\arg \min }[\widehat{\Omega}-\Omega(\theta)]^{\prime} \Upsilon^{-1}[\widehat{\Omega}-\Omega(\theta)],
$$

where $\Upsilon$ is a $k \times k$ positive-definite weighting matrix.

Specifically, $\widehat{\Omega}$ contains the consumer credit moments as shown in Table 1. $\widetilde{\theta}_{S M M}$ contains the estimates for $b, \sigma, \phi, \rho_{\zeta}, \sigma_{\zeta}, \rho_{\nu}$, and $\sigma_{\nu}$. For the weighting matrix, we

15. The SMM approach was proposed by McFadden (1989) and extended by Lee and Ingram (1991), among others. 
follow Ruge-Murcia (2013) and choose a matrix with diagonal elements equal to the optimal weighting matrix while all off-diagonal elements are equal to zero. ${ }^{16}$ Hence, we only put weight on moments that are observed in the data and force the estimation to consider only economically meaningful moments (see Cochrane 2005, chap. 11). Additionally, we follow Born and Pfeifer (2014) and incorporate prior information about the parameters to estimate. In particular, we choose prior means $\bar{\theta}$ for each parameter in $\theta$ and expand $[\widehat{\Omega}-\Omega(\theta)]$ by $\left(\tilde{\theta}_{S M M}-\bar{\theta}\right)$, the deviation of the estimated parameter from the respective prior mean. We expand $\Upsilon$ by attaching small penalty terms to the diagonal, which raise the objective function when deviating from the prior mean. The penalties are of negligible magnitude compared to the other elements in $\Upsilon$ but impose soft bounds on the parameters. ${ }^{17}$ We choose this procedure to rule out local minima in implausible regions of the state space, which is often the case when estimating DSGE models. ${ }^{18}$ Since we want to be agnostic about the strength of the relative consumption motive $b$, we choose a prior mean of 0 so that deviations from zero are only tolerated if they imply significant improvements in the targeted moments.

To rule out dependence on one particular draw of shocks, we draw several sets of shocks and choose the parameter set that minimizes the mean of all objective functions. We use the following algorithm to estimate $\theta$.

Algorithm 1 (Construction of objective function to be minimized). We start with a guess for $\widetilde{\theta}_{S M M}$. Then:

(1) Draw 50 sets of shocks, each consisting of $(\tau T+1500) \times 4$ values.

(2) For each set of shocks: solve the model, simulate time series, discard the first 1500 periods, compute moments, compute objective function.

(3) Take the mean of all 50 objective function values and minimize this.

We set $\tau$ to 10 , implying that the artificial time series are 10 times larger than the original sample size. Ruge-Murcia (2013) shows that this is a useful choice for handling the trade-off between accuracy and computational cost.

Following Ruge-Murcia (2013), we compute the standard errors of $\widetilde{\theta}_{S M M}$ from an estimate of its asymptotic covariance matrix as

$$
(1+1 / \tau)\left(J^{\prime} \Upsilon J\right)^{-1} J^{\prime} \Upsilon J S J\left(J^{\prime} \Upsilon J\right)^{-1},
$$

where $J$ is the Jacobian matrix and $S$ is the full variance-covariance matrix of the empirical moments.

16. Ruge-Murcia (2013) shows that this choice produces consistent parameter estimates, while standard errors are just slightly higher than those generated with the optimal weighting matrix. The optimal weighting matrix is given by the inverse of the variance-covariance matrix associated with the sample moments. We compute this matrix with the VARHAC-estimator with automatic lag selection by the Bayesian information criterion (see Den Haan and Levin 1997).

17. Born and Pfeifer (2014) show that this procedure can be interpreted as using a truncated normal distribution.

18. Also known as the "dilemma of absurd parameter estimates," see An and Schorfheide (2007). 
TABLE 4

Data And Simulated Model Moments

\begin{tabular}{|c|c|c|c|c|c|c|c|c|}
\hline & \multicolumn{2}{|l|}{$\rho\left(x_{t}, D_{t}\right)$} & \multicolumn{2}{|l|}{$\sigma_{x} / \sigma_{D}$} & \multicolumn{2}{|l|}{$\rho\left(x_{t}, Y_{t}\right)$} & \multicolumn{2}{|l|}{$\sigma_{x} / \sigma_{Y}$} \\
\hline & Data & Model & Data & Model & Data & Model & Data & Model \\
\hline Output & 0.1523 & 0.1246 & 0.4568 & 0.3364 & - & - & - & - \\
\hline Consumption & 0.1658 & 0.1548 & 0.2783 & 0.3046 & 0.8020 & 0.7468 & 0.6092 & 0.9059 \\
\hline Investment & 0.0852 & 0.0227 & 1.7524 & 1.0194 & 0.9061 & 0.7086 & 3.8359 & 3.0321 \\
\hline Hours worked & 0.3603 & 0.4112 & 0.5080 & 0.5619 & 0.8144 & 0.6797 & 1.1120 & 1.6717 \\
\hline Real wage & -0.3207 & -0.5422 & 0.3994 & 0.4977 & 0.0023 & -0.2883 & 0.8743 & 1.4819 \\
\hline
\end{tabular}

Note: $\rho\left(x_{t}, D_{t}\right)$ is the cross-correlation of variable $x$ with credit, $\sigma_{x} / \sigma_{D}$ is the std. deviation of variable $x$ relative to the std. deviation of credit, $\rho\left(x_{t}, Y_{t}\right)$ is the cross-correlation of variable $x$ with output, $\sigma_{x} / \sigma_{Y}$ is the std. deviation of variable $x$ relative to the std. deviation of output. Consumer credit has been deflated using the price index of personal consumption expenditures. All variables are logged and HP-filtered (smoothing parameter of 1600) to obtain cyclical components. For data definitions and sources, see Online Appendix A

The results of the SMM estimation are shown in the lower part of Table 3. For $b$, we obtain a value of 2.92 that is estimated to be significantly different from zero, indicating a strong presence of the relative consumption motive. For $\sigma$, we estimate a value of 4.18. To get a better interpretation of these values, we make use of Proposition 2, which quantifies the (partial equilibrium) reaction of workers' consumption to an increase in investors' consumption. Inserting the values of $b$ and $\sigma$ as well as the estimate of the debt adjustment cost parameter $\phi$ into $\xi_{0}$ gives a coefficient of 0.6416 . This implies that a $1 \%$ increase in investors' consumption leads to an increase of about $0.64 \%$ in workers' consumption. This elasticity is in the upper range of estimates provided by Bertrand and Morse (2016), which implies that our estimated model is able to replicate microeconometric evidence on the strength of the keeping up-motive.

The investment specific technology shock is estimated to have a relatively high degree of persistence, whereas the wage markup shock displays a relatively low degree of persistence. Moreover, the standard deviations of both shocks, $\sigma_{\zeta}$ and $\sigma_{\nu}$, are in line with values found by related studies. ${ }^{19}$ The estimated debt adjustment cost parameter $\phi$ takes a value of 0.996 .

Columns $2-5$ of Table 4 report the credit moments obtained from the data and from the model simulations. All these model moments are close to the empirical ones with only minor discrepancies. As in the data, the model dynamics imply positive correlations between credit and consumption, output and hours worked, respectively, whereas the real wage and consumer credit are negatively correlated. Investment does not show a contemporaneous correlation with credit. Also in line with their empirical counterparts, the estimated model implies that output, consumption, hours worked, and the real wage are less volatile than consumer credit, whereas investment displays a higher relative volatility. Thus, the rather negligible differences suggest that our calibration/estimation exercise provides a set of reasonable parameter values and, furthermore, supports the inclusion of the keeping up with the Riches mechanism into the proposed theoretical setup.

19. See, for example, Galí, Gertler, and López-Salido (2007), Iacoviello (2015). 
TABLE 5

Estimated Parameter Values For Both Specifications

\begin{tabular}{lccc}
\hline \hline & Parameter & $b=\hat{b}$ & $b=0$ \\
\hline Relative consumption motive & $b$ & 2.9198 & - \\
Risk aversion parameter & $\sigma$ & 4.1754 & 8.1658 \\
Debt adjustment cost parameter & $\phi$ & 0.9961 & 1.0349 \\
AR-coefficient investment-specific technology shock & $\rho_{\zeta}$ & 0.9181 & 0.7376 \\
Standard deviation investment shock & $\sigma_{\zeta}$ & 0.0102 & 0.0137 \\
AR-coefficient wage markup shock & $\rho_{v}$ & 0.6080 & 0.4976 \\
Standard deviation wage markup shock & $\sigma_{v}$ & 0.0281 & 0.0076 \\
\hline
\end{tabular}

Columns 6-9 of Table 4 show the correlations between output and the remaining four aggregate variables as well as the standard deviations of these aggregates relative to the standard deviation of output. Note that these statistics are not included in the moment-matching approach so that we can interpret these results as the model's ability to replicate important conventional business cycle relations.

Simulating the model leads to a strong procyclical behavior of investment and hours worked with correlation coefficients close to the empirical moments. Moreover, the model produces a strong positive comovement between output and consumption as observed in the data. The implied relative standard deviations of these variables also show a similar magnitude as their empirical counterparts. The only two moments that are qualitatively off are those related to the wage rate. However, recent research has revealed significant changes in the comovements of most labor market variables since the beginning of the Great Moderation (e.g., Galí and Gambetti 2009, Andrés, Boscá, and Ferri 2013). Reproducing the acyclical behavior of real wages documented in Table 4 therefore poses a challenge for most macroeconomic models. Nevertheless, the differences between the two sets of moments are only small-sized so that we interpret the results of this quantitative exercise as a validation of our proposed model and the underlying calibration/estimation strategy.

\subsection{Estimation Without b}

In the following, we demonstrate that our proposed model that includes the relative consumption motive outperforms the model in which the relative consumption motive is excluded. In doing so, we repeat our model estimation but set $b=0$ so that we abstract from any consumption externalities. Table 5 shows the estimated parameters of this exercise and compares them to our baseline estimation, which includes the relative consumption motive. It turns out that some parameters for the model with $b=0$ alter drastically compared to the baseline case. In particular, $\sigma$ is estimated to be significantly larger than in our baseline case. This is not surprising as the baseline estimation suggests a strong consumption smoothing channel, as specified in Proposition 1. To achieve a similar strength of the channel in absence of $b, \sigma$ has to be considerably higher than in the baseline. 
TABLE 6

Data And Simulated Model Moments For Both Specifications

\begin{tabular}{|c|c|c|c|c|c|c|}
\hline & \multicolumn{3}{|c|}{$\rho\left(x_{t}, D_{t}\right)$} & \multicolumn{3}{|c|}{$\sigma_{x} / \sigma_{D}$} \\
\hline & Data & $b=\hat{b}$ & $b=0$ & Data & $b=\hat{b}$ & $b=0$ \\
\hline Output & 0.1523 & 0.1246 & -0.0320 & 0.4568 & 0.3364 & 0.2743 \\
\hline Consumption & 0.1658 & 0.1548 & 0.0743 & 0.2783 & 0.3046 & 0.2348 \\
\hline Investment & 0.0852 & 0.0227 & -0.0643 & 1.7524 & 1.0194 & 1.5863 \\
\hline Hours worked & 0.3603 & 0.4112 & 0.6418 & 0.5080 & 0.5619 & 0.5008 \\
\hline \multirow[t]{3}{*}{ Real wage } & -0.3207 & -0.5422 & -0.7265 & 0.3994 & 0.4977 & 0.6804 \\
\hline & \multicolumn{3}{|c|}{$\rho\left(x_{t}, Y_{t}\right)$} & \multicolumn{3}{|c|}{$\sigma_{x} / \sigma_{Y}$} \\
\hline & Data & $b=\hat{b}$ & $b=0$ & Data & $b=\hat{b}$ & $b=0$ \\
\hline Consumption & 0.8020 & 0.7468 & -0.1286 & 0.6092 & 0.9059 & 0.8567 \\
\hline Investment & 0.9061 & 0.7086 & 0.8538 & 3.8359 & 3.0321 & 5.7848 \\
\hline Hours worked & 0.8144 & 0.6797 & 0.0245 & 1.1120 & 1.6717 & 1.8296 \\
\hline Real wage & 0.0023 & -0.2883 & 0.1160 & 0.8743 & 1.4819 & 2.4864 \\
\hline
\end{tabular}

Note: $\rho\left(x_{t}, D_{t}\right)$ is the cross-correlation of variable $x$ with credit, $\sigma_{x} / \sigma_{D}$ is the std. deviation of variable $x$ relative to the std. deviation of credit.

The model in which $b=0$ performs worse in replicating the credit moments compared to our proposed setup. As Table 6 shows, the model that excludes upward looking consumption comparison does neither reproduce the positive correlation between credit and output nor the positive correlation between investment and credit. Instead, both correlations are negative, although only slightly. Moreover, when $b=0$, the positive correlation between consumption and credit is considerably smaller. Furthermore, both the positive correlation between credit and hours worked and the negative correlation between credit and the wage rate are considerably larger than in the data. In addition, the model that abstracts from the consumption externality induces a negative correlation between output and consumption, which stands in sharp contrast to the data. This counterintuitive relation is a result of the high estimated risk aversion that decouples aggregate consumption from the business cycle. We show below that two of the four shocks are specifically responsible for this result as they imply a negative relation between output and consumption when $b=0$.

To conclude, we see the worse credit correlations and overall output moments implied by the model that does not include the relative consumption motive as a further justification of our proposed model mechanism. Including the keeping up parameter significantly improves the model's ability to match the data.

\section{MODEL DYNAMICS}

In the previous section, we have shown that our proposed four-shock model successfully replicates the empirical credit moments. Now, we investigate the model 
dynamics induced by each of the four shocks separately. Table 7 presents the credit moments obtained from simulating our model where dynamics are driven by just one of the four shocks. Afterward, we present impulse responses for the two different model estimations, the unrestricted baseline estimation and the restricted estimation with $b=0$ from Section 3.4, to highlight the impact of the keeping up mechanism.

\subsection{Moment Analysis}

The upper part of Table 7 reports the correlations between credit and the respective macroeconomic aggregate for each shock separately. We find for the unrestricted model that the price markup and the investment-specific technology shock lead to a positive comovement between credit and output as well as between credit and consumption. The remaining two shocks produce negative correlations between credit and output and credit and consumption irrespective of the inclusion of keeping up behavior. In contrast to the unrestricted estimation, the price markup shock leads to a strong negative correlation between credit and consumption for the model that abstracts from consumption externalities. Moreover, the investment-specific technology shock produces a negative correlation between credit and output and credit and investment, while the former correlation is positive when estimating $b$. In this case, the neutral technology, price markup, and investment-specific technology shock also induce a positive correlation between credit and hours worked and a negative comovement between credit and wages, perfectly in line with the data. Clear differences between the responses of both model estimations can be observed for the price markup and the investment-specific shock. As we will explain in more detail in the next subsections, the price markup and the investment-specific technology shock are of major importance in reproducing procyclical credit dynamics.

Turning to the relative standard deviations, we see for the unrestricted estimation that both markup shocks and the neutral technology shock lead to output, consumption, and hours dynamics that are less volatile than the respective credit dynamics. The investment-specific technology shock, on the other hand, produces consumption and hours series that are more volatile than credit, while investment exhibits less volatility. The latter is also true for the neutral technology and the wage markup shock in the unrestricted parameterization. In contrast, only the price markup shock induces investment responses that are more volatile than the credit ones. All four shocks produce wage series that are less volatile than the simulated credit series.

We can use our model simulation also to gain some insights into how relative income and consumption fluctuate over the business cycle. For this purpose, we construct a series for consumption and income inequality, respectively. ${ }^{20}$ As the third part of Table 7 reports, consumption and income inequality are positively correlated with credit, implying that an increase in inequality is accompanied by a rise in credit. This holds true irrespective of estimating $b$ or setting $b=0$. Nevertheless, the

20. Consumption inequality is defined as the ratio between investors' consumption and workers' consumption. Income inequality is defined as the ratio between investors' income (the sum of profits, income from physical capital and income from deposits) and workers' income (labor income). 
24 : MONEY, CREDIT AND BANKING

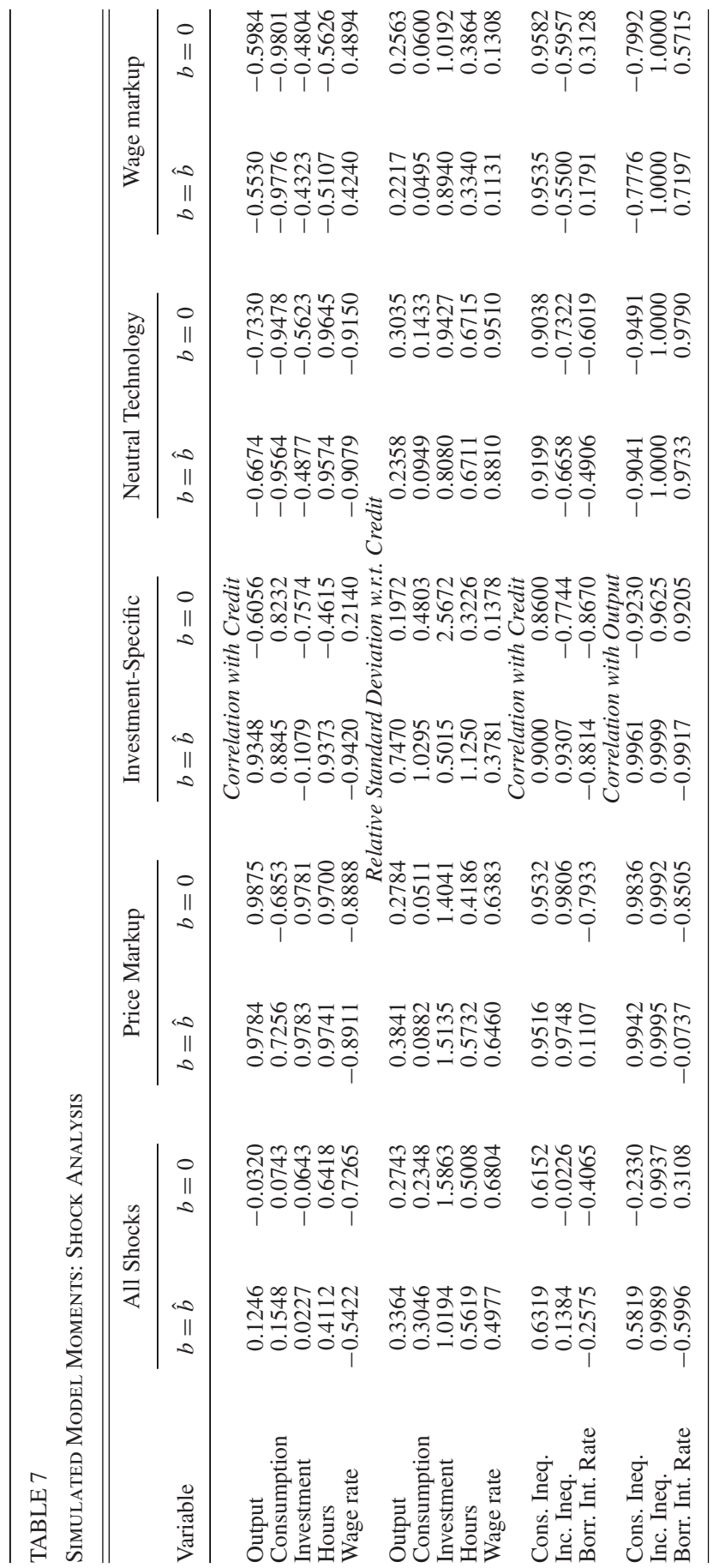


correlation between consumption inequality and credit is slightly stronger when we estimate $b$. This finding is supported by the evidence of Bertrand and Morse (2016), Georgarakos, Haliassos, and Pasini (2014) who find that growing inequality is positively associated with an increase in consumer credit. Overall, we find that both the markup shocks produce the strongest correlation between consumption inequality and credit, irrespective of $b$.

Consumption and income inequality are both positively correlated with output when estimating $b$, implying a widening (narrowing) of income and consumption differences in a boom (recession). While all shocks generate more or less a perfect correlation between output and income inequality, the procyclicality of consumption inequality is driven by shocks to price markup and investment. When setting $b=0$ consumption inequality is countercyclical, whereas income inequality shows a strong procyclical pattern, as all shocks generate this result. ${ }^{21}$

We also investigate how the borrowing interest rate behaves in both model versions. Irrespective of estimating $b$ or setting $b=0$, the interest rate is negatively correlated with credit, implying lower (higher) credit costs when credit markets become loose (tight). Turning to the correlation with output, we find for the unrestricted estimation that the borrowing interest rate behaves countercyclical such that the credit price goes up (down) when output is high (low). ${ }^{22}$ This negative correlation is mainly driven by dynamics due to the investment-specific shock. Contrary, when restricting $b$, we find a procyclical borrowing interest rate mainly due to both technology shocks.

To get a better understanding of the keeping up mechanism, in the following, we discuss in more detail impulse responses. We focus here on the two most important shocks in our model, the price markup shock and the investment-specific technology shock. ${ }^{23}$

\subsection{Price Markup Shock}

Figure 1 presents the model responses to a price markup shock. The shock leads to a falling wage rate while not affecting the marginal product of labor. A similar effect can be observed for the rental rate of capital. Due to lower marginal cost, profits rise so that investors obtain a higher income, and increase their consumption level and investment. If the relative consumption motive is present (solid lines), working households respond by increasing their consumption level as well. They derive the additionally required income through two sources. First, workers raise their labor supply and second, they enhance their demand for credit so that the drop in labor

21. The cyclical behavior of income inequality is still an open question in the literature. While some studies find that income inequality moves countercyclical (Heathcote, Perri, and Violante 2010), others detect a procyclical behavior especially during the Great Moderation during which inequality increased significantly (Morin 2019, Galbraith 2009). Moreover, note that our inequality measures are based on just two representative households and should therefore not be directly compared to commonly used inequality measures that take the whole income (consumption) distribution into account.

22. This is in line with the mechanism in Nakajima and Ríos-Rull (2014) who consider not only neutra technology shocks but also countercyclical wage risk.

23. Impulse responses for the neutral technology shock and the wage markup shock can be found in Online Appendix C. 

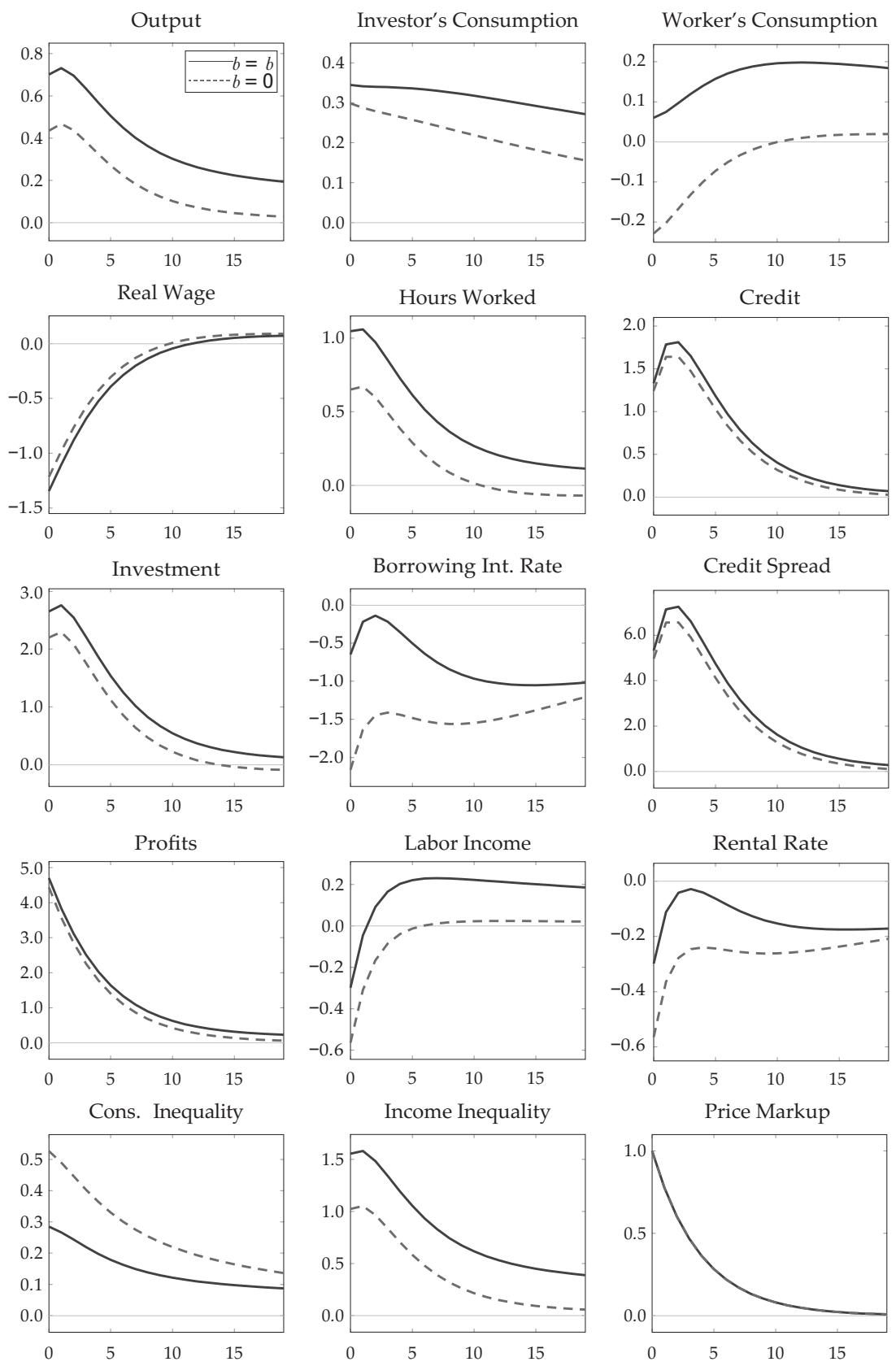

Fig 1. Impulse Responses to Price Markup Shock.

NotE: Responses are measured in percentage deviations from steady state. Horizontal axes measure time in quarters. 
income, defined as the product of the real wage and hours worked, is almost fully compensated. The increase in credit is enhanced by a falling borrowing interest rate. As investment and hours worked rise, aggregate output also goes up when the price markup shock hits the economy.

The outcome changes if we abstract from the relative consumption motive (dashed lines). Now, the workers' choice of consumption does not hinge on the investors anymore. In this case, workers increase their labor supply by a smaller amount and reduce their consumption expenditures. As a result, the drop in labor income is more pronounced and output goes up to a lesser extent.

Consumption inequality rises in both scenarios but significantly less when the relative consumption motive is present. Income inequality is also strongly increasing after a price markup shock, caused by large profits on the investors' side while labor income drops on impact and rises only moderately over time.

\subsection{Investment-Specific Technology Shock}

Figure 2 presents the model responses to an investment-specific technology shock. In the unrestricted model (solid lines), investors shift their expenditures from consumption to investment on impact, as the shock makes saving in capital more profitable. Since workers imitate the consumption behavior of investors, they also decrease their consumption expenditures. This results in a reduced supply of hours worked and a falling demand for credit. As credit falls, the interest rate goes up, although not as much as the interest rate on deposits, so that the credit spread decreases ultimately. The strong decrease in labor supply leads then to a fall in aggregate output and profits, resulting in a significant decrease of investors' income and their personal expenditures. The negative responses of most aggregate variables is supported by empirical evidence showing that investment-specific technology shocks have contractionary effects (Basu et al. 2013).

The results change significantly when the consumption externality is switched off (dashed lines). Working households now increase their labor supply and reduce their credit demand by a smaller amount so that the reduction in consumption expenditures is only marginal. Similarly, the investors' consumption level drops less pronounced, also due to an increase in profits. Consequently, the rise in investment is more persistent and as both input factors increase also output goes up when the relative consumption motive is absent.

Consumption inequality drops strongly as investors decrease their consumption expenditures relatively more than workers in both scenarios. Income inequality, on the other hand, decreases when the relative consumption motive is present and rises otherwise. In the former case, investors experience a decline in profits and capital income as the rental rate drops sharply. Since both types lose in terms of income but the investors relatively more, income inequality decreases. In the other case, the opposite is true. Both types' income increases but investors gain relatively more so that inequality in income increases slightly. 

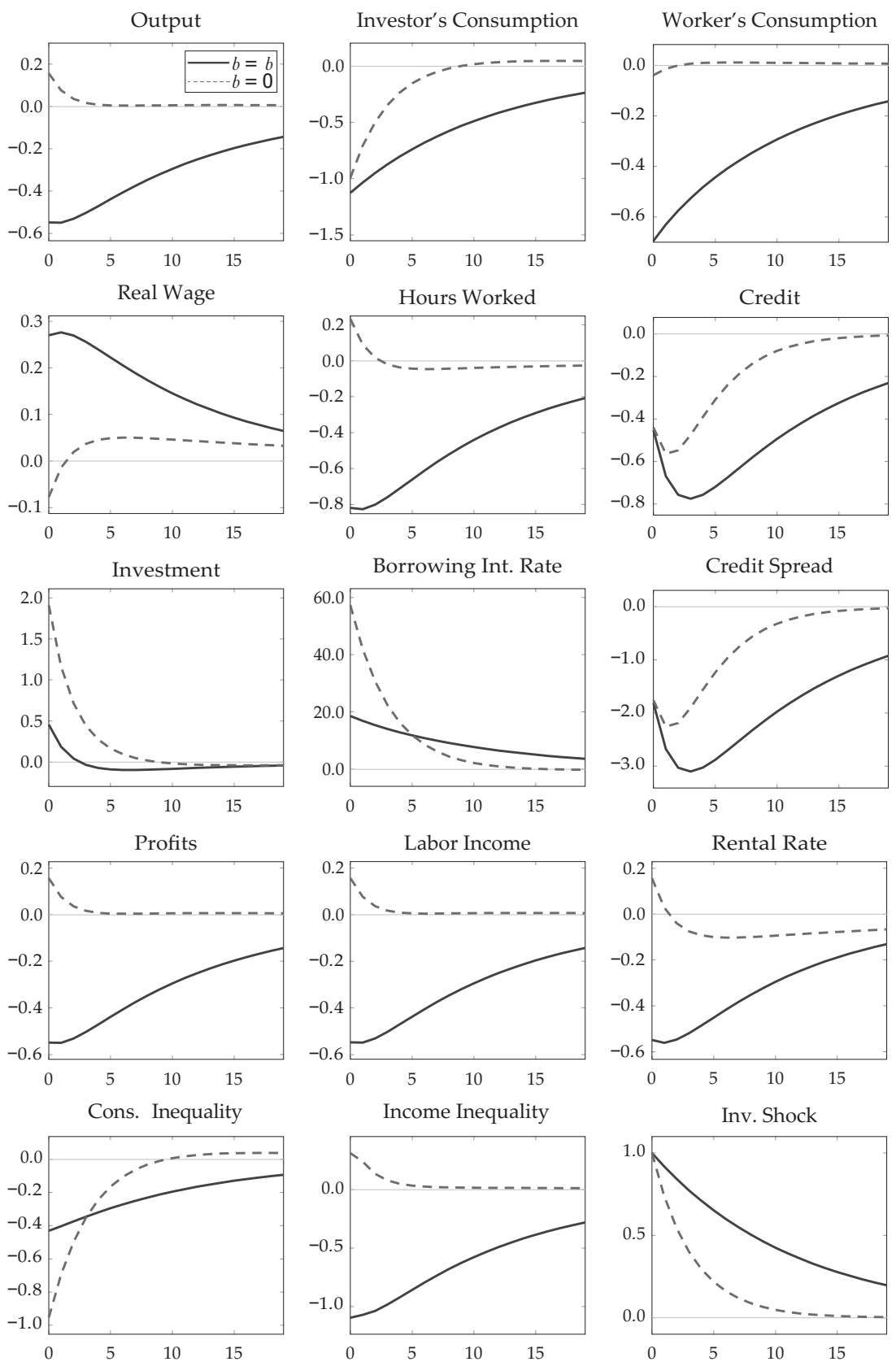

Fig 2. Impulse Responses to Investment-Specific Technology Shock.

NoTE: Responses are measured in percentage deviations from steady state. Horizontal axes measure time in quarters. 


\section{ROBUSTNESS}

In this section, we show that our results are robust when modifying the externality such that it is based on lagged relative consumption. More specifically, we investigate a catching up behavior instead of keeping up. In a second robustness exercise, we split the sample and study whether the degree of upward looking comparison has changed over time. ${ }^{24}$

\subsection{Catching Up with the Riches}

First, we adjust the reference point of workers in equation (23). Instead of assuming that $X$ enters contemporaneously, workers' utility depends here on past relative consumption. ${ }^{25}$ Thus, the workers' utility function becomes

$$
U\left(C_{w, t}, X_{t-1}, N_{w, t}\right)=\frac{\left(C_{w, t} X_{t-1}^{-b}\right)^{1-\sigma}-1}{1-\sigma}-\frac{\gamma N_{w, t}^{1+\eta}}{1+\eta}, \quad \text { with } X_{t-1}:=\frac{C_{i, t-1}}{C_{w, t-1}},
$$

where $b$ again determines the strength of the relative consumption motive. The focus on past relative consumption might be justified by the fact that agents need time to observe and realize other agents' consumption decisions, and to adjust their own consumption expenditures. We run the same procedure as with our baseline specification, namely, estimate the vector of parameters $\theta^{*}=\left\{b, \sigma, \phi, \rho_{\zeta}, \sigma_{\zeta}, \rho_{\nu}, \sigma_{\nu}\right\}$ by SMM. The upper part of Table 8 reports the estimated parameters for this specification.

We find that the parameter governing the catching up preferences is positive and significant, but somewhat smaller as for the keeping up preferences. Moreover, the risk aversion parameter $\sigma$ slightly increases. The remaining parameters are similar to the baseline estimates.

The lower part of Table 8 reports the simulated moments in comparison to their empirical counterparts. We find an overall good fit with this preference specification as all of the targeted moments are in line with the data. In terms of the nontargeted moments in columns 6-9, we detect a slightly different pattern compared to our baseline case. The model with catching up preferences is able to replicate the acyclicality of the real wage. This comes at the cost of a relatively lower procyclicality of consumption, investment, and hours worked, and a much more volatile real wage series such that wages are more than twice a volatile as in the data.

24. Online Appendix D includes additional robustness exercises. In particular, we exclude parameter $\sigma$ from the estimation procedure, we investigate the sensitivity of our results with respect to the choice of the inverse Frisch elasticity $\eta$. Additionally, we allow for different specifications of the externality $X_{t}$.

25. In analogy to Abel (1990), we call this catching up with the Riches. 
TABLE 8

Estimated Parameter Values With Catching Up Preferences

\begin{tabular}{|c|c|c|c|c|c|c|c|c|}
\hline & & & & \multicolumn{2}{|c|}{ Parameter } & \multicolumn{2}{|l|}{ Value } & $S D$ \\
\hline \multicolumn{4}{|c|}{ Relative consumption motive } & $b$ & \multicolumn{2}{|r|}{0.8914} & \multicolumn{2}{|r|}{$(0.0418)$} \\
\hline \multicolumn{4}{|c|}{ Risk aversion parameter } & $\sigma$ & & 4.6662 & \\
\hline \multicolumn{4}{|c|}{ Debt adjustment cost parameter } & $\phi$ & & 1.0948 & \multicolumn{2}{|r|}{$\begin{array}{l}(0.0532) \\
(0.0187)\end{array}$} \\
\hline \multicolumn{4}{|c|}{ AR-coefficient inv.-specific technology shock } & $\rho_{\zeta}$ & & 0.8460 & \multicolumn{2}{|r|}{$\begin{array}{l}(0.0187) \\
(0.0301)\end{array}$} \\
\hline \multicolumn{4}{|c|}{ Standard deviation investment shock } & $\sigma_{\zeta}$ & & 0.0098 & \multicolumn{2}{|r|}{$\begin{array}{l}(0.0301) \\
(0.0005)\end{array}$} \\
\hline \multirow{2}{*}{\multicolumn{4}{|c|}{ Standard deviation wage markup shock }} & $\rho_{v}^{s}$ & & 0.6384 & & (0.1901) \\
\hline & & & & $\sigma_{v}$ & & 0.0193 & \multicolumn{2}{|r|}{$(0.0033)$} \\
\hline & \multicolumn{2}{|c|}{$\rho\left(x_{t}, D_{t}\right)$} & \multicolumn{2}{|c|}{$\sigma_{x} / \sigma_{D}$} & \multicolumn{2}{|c|}{$\rho\left(x_{t}, Y_{t}\right)$} & \multicolumn{2}{|c|}{$\sigma_{x} / \sigma_{Y}$} \\
\hline & Data & Model & Data & Model & Data & Model & Data & Model \\
\hline Output & 0.1523 & 0.0847 & 0.4568 & 0.3041 & - & - & - & - \\
\hline Consumption & 0.1658 & 0.1465 & 0.2783 & 0.2955 & 0.8020 & 0.5083 & 0.6092 & 0.9729 \\
\hline Investment & 0.0852 & -0.0301 & 1.7524 & 1.2405 & 0.9061 & 0.6846 & 3.8359 & 4.0820 \\
\hline Hours worked & 0.3603 & 0.4951 & 0.5080 & 0.5007 & 0.8144 & 0.3116 & 1.1120 & 1.6494 \\
\hline Real wage & -0.3207 & -0.5250 & 0.3994 & 0.6024 & 0.0023 & 0.0172 & 0.8743 & 1.9853 \\
\hline
\end{tabular}

NotE: $\rho\left(x_{t}, D_{t}\right)$ is the cross-correlation of variable $x$ with credit, $\sigma_{x} / \sigma_{D}$ is the std. deviation of variable $x$ relative to the std. deviation of credit, $\rho\left(x_{t}, Y_{t}\right)$ is the cross-correlation of variable $x$ with output, $\sigma_{x} / \sigma_{Y}$ is the std deviation of variable $x$ relative to the std. deviation of output. Consumer credit has been deflated using the price index of personal consumption expenditures. All variables are logged and HP-filtered (smoothing parameter of 1600) to obtain cyclical components. For data definitions and sources, see Online Appendix A.

The intuition behind these results is the following. Consider the workers' (loglinearized) Euler equation abstracting from debt adjustment costs, given by

$$
\begin{aligned}
& \widehat{C}_{w, t+1}-\frac{(b(1-\sigma)+\sigma)}{\sigma} \widehat{C}_{w, t}+\frac{b(1-\sigma)}{\sigma} \widehat{C}_{w, t-1} \\
& =-\frac{1}{\sigma} \widehat{Q}_{t}+\frac{b(\sigma-1)}{\sigma}\left(\widehat{C}_{i, t}-\widehat{C}_{i, t-1}\right) .
\end{aligned}
$$

As compared to Proposition 1, catching up preferences introduce an additional lagged consumption term to the workers' Euler equation. This is an additional internal habit channel that simplifies consumption smoothing so that a lower $b$ is necessary to get the targeted moments.

The acyclicality of the real wage, on the other hand, is related to the estimated shock parameters of both the investment-specific technology shock and the wage markup shock. Both shocks induce a negative correlation between output and the real wage, and since both have a smaller estimated standard deviation, this leads to a less negative correlation.

When comparing keeping up to catching up, we conclude that the latter are slightly inferior when it comes to matching second moments as the keeping up preferences match 6 of 10 targets better and 5 of 8 nontargeted moments. 
TABLE 9

ESTIMATED PARAMETERS AND SIMULATED MOMENTS FOR BOTH SUBSAMPLES

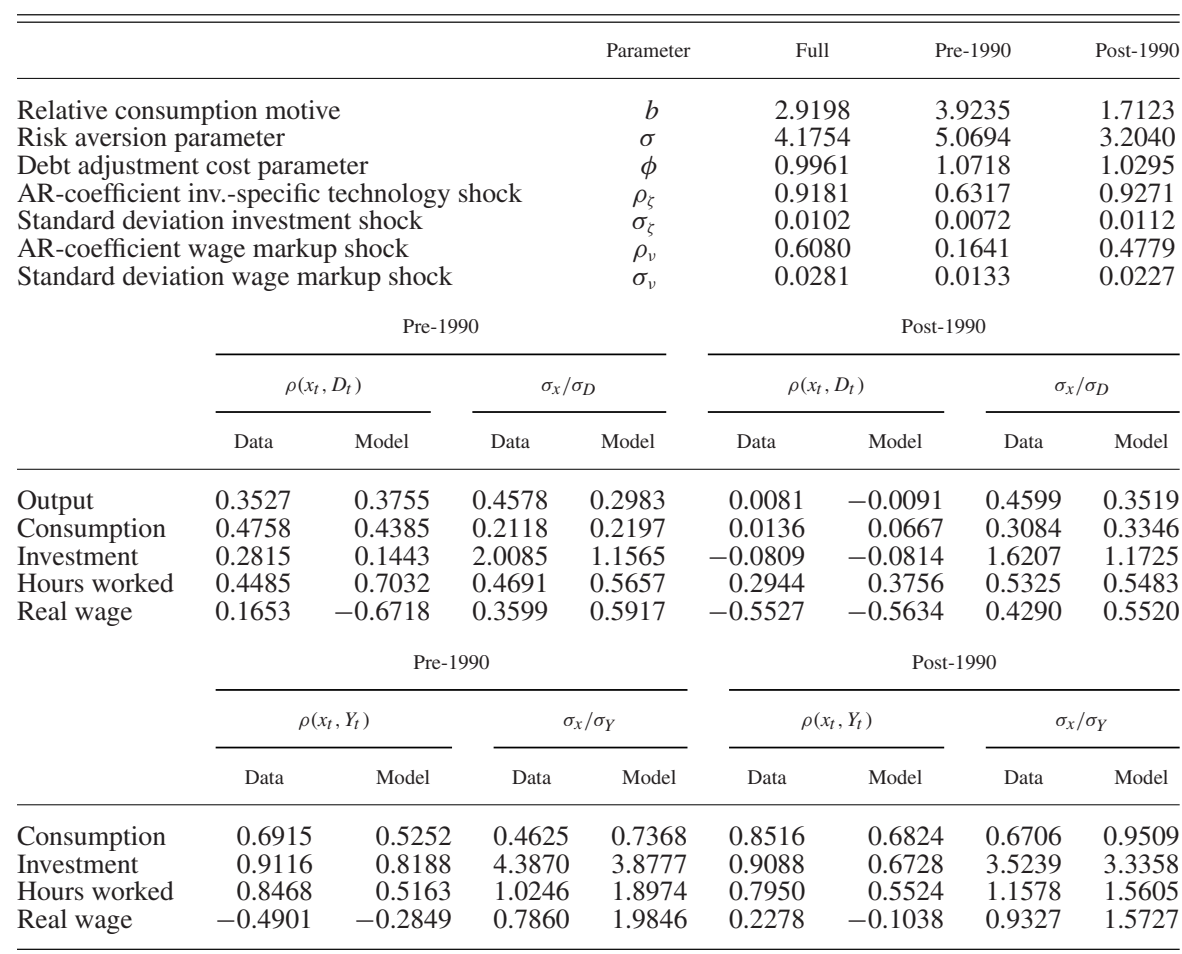

Note: $\rho\left(x_{t}, D_{t}\right)$ is the cross-correlation of variable $x$ with credit, $\sigma_{x} / \sigma_{D}$ is the std. deviation of variable $x$ relative to the std. deviation of credit. $\rho\left(x_{t}, Y_{t}\right)$ is the cross-correlation of variable $x$ with output, $\sigma_{x} / \sigma_{Y}$ is the std. deviation of variable $x$ relative to the std. deviation of output.

\subsection{Split-Sample Estimation}

As a final check, we test whether our findings are robust when splitting the sample. As shown by Fieldhouse, Livshits, and MacGee (2016) the cyclical behavior of credit has shifted during the early 1990s. As Table 9 reports, we indeed find a change in the cyclicality of consumer credit. In particular, we split the full sample into one pre-1990 and one post-1990 sample and find that credit is strongly procyclical in the first part of the sample, whereas it turns mainly acyclical thereafter. This result might suggest that also the strength of the keeping up mechanism has changed over time.

To investigate this issue, we estimate our model parameters for both subsamples. As expected, the size of the relative consumption motive is much stronger in the pre1990 sample than in the post-1990 sample. The parameter is estimated to be more than twice as large in the first subsample. However, also in the second subsample, we find a positive value for $b$, which indicates that relative consumption concerns are still an important determinant of credit dynamics in the more recent part of the sample. For both subsamples, the model produces credit dynamics that show only 
minor discrepancies compared to the empirical ones. Moreover, the nontargeted output moments match the observed ones fairly closely pre- and post-1990. Overall, we conclude that, while the strength of the relative consumption motive has decreased over time, our estimation on the more recent past still strongly speaks in favor of consumption externalities.

\section{CONCLUSION}

In this paper, we set up a DSGE model that mimics the short-run dynamics of consumer credit for the period of the Great Moderation. The model consists of two different household types. Investors, who hold the economy's entire capital stock, own the firms and supply credit, and workers who make up the entire labor force and demand credit to finance their desired level of consumption. In addition, we incorporate a keeping up with the Riches mechanism so that workers aim to keep up with the investors' level of consumption.

When estimating deep model parameters, we find a positive significant value for the workers' keeping up parameter. Qualitatively, an income redistribution from labor to capital and an investment-specific technology shock lead to model dynamics that are perfectly in line with the empirical evidence. More precisely, both shocks generate positive correlations of consumer credit with output, consumption, and labor, while there is a negative comovement between consumer credit and the real wage. In contrast, a neutral technology shock and a wage markup shock are not able to generate the positive correlations between consumer credit, output, and consumption. In reproducing empirical credit moments, the proposed model significantly outperforms a model version in which consumption externalities are not included. Complementary to microevidence (Bertrand and Morse 2016), we have provided macroevidence on the link between income redistribution, consumption externalities, and credit dynamics.

We think that a potential promising area of future research lies in extending our proposed model by strategic default. In particular, combining incomplete markets and default on unsecured credit as studied by Livshits, MacGee, and Tertilt (2007), Chatterjee et al. (2007) with relative consumption concerns might provide important insights in terms of business cycle fluctuations and welfare costs that are of great interest not only for the research community but also for policymakers.

\section{LITERATURE CITED}

Abel, Andrew B. (1990) "Asset Prices under Habit Formation and Catching up with the Joneses.” American Economic Review, 80, 38-42.

Airaudo, Marco, and Luca Bossi. (2017) "Consumption Externalities and Monetary Policy with Limited Asset Market Participation.” Economic Inquiry, 55, 601-23. 
Alvarez-Cuadrado, Francisco, and Irakli Japaridze. (2017) "Trickle-Down Consumption, Financial Deregulation, Inequality, and Indebtedness." Journal of Economic Behavior and Organization, 134, 1-26.

An, Sungbae, and Frank Schorfheide. (2007) "Bayesian Analysis of DSGE Models." Econometric Reviews, 26, 113-172.

Andrés, Javier, José E. Boscá, and Javier Ferri. (2013) "Household Debt and Labor Market Fluctuations." Journal of Economic Dynamics \& Control, 37, 1771-95.

Basu, Susanto, John Fernald, Jonas Fisher, and Miles Kimball. (2013) "Sector-Specific Technical Change." Unpublished manuscript, Federal Reserve Bank of San Francisco.

Bertrand, Marianne, and Adair Morse. (2016) “Trickle-Down Consumption." Review of Economics and Statistics, 98, 863-79.

Born, Benjamin, and Johannes Pfeifer. (2014) "Policy Risk and the Business Cycle." Journal of Monetary Economics, 68, 68-85.

Bullard, James, and Aarti Singh. (2012) "Learning and the Great Moderation." International Economic Review, 53, 375-97.

Carr, Michael D., and Arjun Jayadev. (2015) "Relative Income and Indebtedness: Evidence from Panel Data." Review of Income and Wealth, 61, 759-72.

Chari, V.V., Patrick J. Kehoe, and Ellen R. McGrattan. (2007) "Business Cycle Accounting." Econometrica, 75, 781-836.

Chatterjee, Satyajit, Dean Corbae, Makoto Nakajima, and José-Víctor Ríos-Rull. (2007) “A Quantitative Theory of Unsecured Consumer Credit with Risk of Default." Econometrica, $75,1525-89$.

Cochrane, John H. (2005) Asset Pricing: Revised Edition. Princeton, NJ: Princeton University Press.

Coibion, Olivier, Yuriy Gorodnichenko, Marianna Kudlyak, and John Mondragon. (2014) "Does Greater Inequality Lead to More Household Borrowing? New Evidence from Household Data." NBER Working Paper 19850.

Cúrdia, Vasco, and Michael Woodford. (2010) "Credit Spreads and Monetary Policy.” Journal of Money, Credit and Banking, 42, 3-35.

Den, Haan, Wouter J., and Andrew T. Levin. (1997) “A Practitioner's Guide to Robust Covariance Matrix Estimation.” In Handbook of Statistics, edited by G. S. Maddala and C. R. Rao, volume 15, pp. 299-342. Amsterdam: Elsevier.

Drechsel-Grau, Moritz, and Kai D. Schmid. (2014) "Consumption-Savings Decisions under Upward-Looking Comparisons.” Journal of Economic Behavior \& Organization, 106, 25468.

Dupor, Bill, and Wen-Fang Liu. (2003) "Jealousy and Equilibrium Overconsumption." American Economic Review, 93, 423-28.

Erceg, Christopher J., Dale W. Henderson, and Andrew T. Levin. (2000) "Optimal Monetary Policy with Staggered Wage and Price Contracts." Journal of Monetary Economics, 46, 281313.

Fernald, John G. (2014) "A Quarterly, Utilization-Adjusted Series on Total Factor Productivity." Working Paper 2012-19, Federal Reserve Bank of San Francisco.

Fieldhouse, David, Igor Livshits, and James MacGee. (2016) “Aggregate Fluctuations, Consumer Credit and Bankruptcy." Unpublished manuscript. 
Galbraith, James K. (2009) "Inequality, Unemployment and Growth: New Measures for Old Controversies." Journal of Economic Inequality, 7, 189-206.

Galí, Jordi. (1994) "Keeping Up with the Joneses: Consumption Externalities, Portfolio Choice, and Asset Prices." Journal of Money, Credit and Banking, 26, 1-8.

Galí, Jordi, and Luca Gambetti. (2009) "On the Sources of the Great Moderation.” American Economic Journal: Macroeconomics, 1, 26-57.

Galí, Jordi, Mark Gertler, and J. David López-Salido. (2007) "Markups, Gaps, and the Welfare Costs of Business Fluctuations." Review of Economics and Statistics, 89, 44-59.

Georgarakos, Dimitris, Michael Haliassos, and Giacomo Pasini. (2014) "Household Debt and Social Interactions." Review of Financial Studies, 27, 1404-33.

Hall, Robert E. (2009) "Reconciling Cyclical Movements in the Marginal Value of Time and the Marginal Product of Labor." Journal of Political Economy, 117, 281-323.

Heathcote, Jonathan, Fabrizio Perri, and Giovanni L. Violante. (2010) "Unequal We Stand: An Empirical Analysis of Economic Inequality in the United States, 1967-2006." Review of Economic Dynamics, 13, 15-51.

Iacoviello, Matteo. (2015) "Financial Business Cycles." Review of Economic Dynamics, 18, 140-64.

Iacoviello, Matteo, and Marina Pavan. (2013) "Housing and Debt over the Life Cycle and over the Business Cycle." Journal of Monetary Economics, 60, 221-38.

Justiniano, Alejandro, Giorgio E. Primiceri, and Andrea Tambalotti. (2010) "Investment Shocks and Business Cycles." Journal of Monetary Economics, 57, 132-45.

Karabarbounis, Loukas. (2014) “The Labor Wedge: MRS vs. MPN.” Review of Economic Dynamics, 17, 206-23.

Lansing, Kevin J., and Agnieszka Markiewicz. (2018) “Top Incomes, Rising Inequality and Welfare." Economic Journal, 128, 262-97.

Lee, Bong-Soo, and Beth Fisher Ingram. (1991) "Simulation Estimation of Time-Series Models." Journal of Econometrics, 47, 197-205.

Livshits, Igor. (2015) "Recent Developments in Consumer Credit and Default Literature." Journal of Economic Surveys, 29, 594-613.

Livshits, Igor, James MacGee, and Michéle Tertilt. (2007) "Consumer Bankruptcy: A Fresh Start." American Economic Review, 97, 402-18.

McFadden, Daniel L. (1989) "A Method of Simulated Moments for Estimation of Discrete Response Models without Numerical Integration.” Econometrica, 57, 995-1026.

Morin, Annaig. (2019) "Wage Dispersion over the Business Cycle." Economics Letters, 181, $17-21$.

Nakajima, Makoto, and José-Víctor Ríos-Rull. (2014) "Credit, Bankruptcy, and Aggregate Fluctuations." NBER Working Paper 20617.

Ruge-Murcia, Francisco J. (2013) "Estimating Nonlinear DSGE Models by the Simulated Method of Moments: With an Application to Business Cycles." Journal of Economic Dynamics \& Control, 36, 914-38.

Schmitt-Grohé, Stephanie, and Martín Uribe. (2003) "Closing Small Open Economy Models." Journal of International Economics, 61, 163-85.

Schmitt-Grohé, Stephanie, and Martín Uribe. (2011) "Business Cycles with a Common Trend in Neutral and Investment-Specific Productivity." Review of Economic Dynamics, 14, $122-35$. 
Smets, Frank, and Raf Wouters. (2003) "An Estimated Dynamic Stochastic General Equilibrium Model of the Euro Area." Journal of the European Economic Association, 1, 1123-75.

Stock, James H., and Mark W. Watson. (1999) "Forecasting Inflation.” Journal of Monetary Economics, 44, 293-335.

\section{SUPPORTING INFORMATION}

Additional supporting information may be found online in the Supporting Information section at the end of the article. 